\title{
A Novel Technique of Transpedicular Opening- wedge Osteotomy for Treatmtent of Rigid Kyphosis in Patients With Ankylosing Spondylitis
}

\section{Guangbin Zheng}

Taizhou Hospital of Zhejiang Province

Zhenghua Hong ( $\square$ hongzh@enzemed.com )

Wenzhou Medical University

zhangfu Wang

Taizhou Hospital of Zhejiang Province

Binbin Zheng

Taizhou Hospital of Zhejiang Province

Research article

Keywords: transpedicular, opening-wedge osteotomy, ankylosing spondylitis, thoracolumbar kyphosis

Posted Date: August 30th, 2021

DOI: https://doi.org/10.21203/rs.3.rs-823509/v1

License: (c) (i) This work is licensed under a Creative Commons Attribution 4.0 International License.

Read Full License 


\section{Abstract}

\section{Background}

To investigate the effectiveness and feasibility of a novel vertebral osteotomy technique, transpedicular opening-wedge osteotomy (TOWO) for correcting rigid thoracolumbar kyphotic deformity in patients with ankylosing spondylitis (AS).

\section{Methods}

18 AS patients underwent TOWO for correcting rigid thoracolumbar kyphosis. Radiographic parameters were compared before surgery, 1 week after surgery and at last follow-up. SRS-22 questionnaire was assessed before surgery and at last follow-up to evaluate clinical improvement. The operating time, estimated blood loss and complications were analyzed.

\section{Results}

The mean operating time and estimated blood loss were 236 minutes and $595 \mathrm{ml}$, respectively. Sagittal parameters improved significantly after surgery. The height of anterior column of osteotomized vertebrae was increased significantly at 1 week after surgery and last follow-up when compared to preoperative, but the height of middle column did not changed significantly. SRS-22 scores were improved significantly at last follow-up than preoperative. Solid fusion was achieved in all patients after 12 months follow-up, no screw loosening, screw pull out or rod breakage was noticed at last follow-up.

\section{Conclusions}

TOWO could achieve a satisfactory kyphosis correction by opening anterior column instead of vertebral body decancellation and posterior column closing, which simplified the osteotomy procedure and improved the surgical efficacy.

\section{Introduction}

Ankylosing spondylitis (AS) is a chronic inflammatory rheumatic disease that mainly involves axial skeleton, leading to the spinal kyphosis which decreases the patients' quality of life [1]. Physical exercise or rehabilitation could not prevent the deformity progression, for severe spinal kyphotic patients who could not look ahead or lie flat, surgical treatment of spinal osteotomy has been proved to be the most effective method [2-4]. Various kinds of osteotomy techniques were introduaced for the spinal kyphosis correction previously, including Smith-Petersen osteotomy (SPO), pedicle substraction osteotomy (PSO), closing opening wedge osteotomy (COWO), vertebral column decancellation (VCD) and vertebral column resection (VCR) [4-8]. SPO is an opening wedge osteotomy (OWO) with the hinge at the posterior aspect of the disc space by widening the anterior disc space which could achieve approximately $10^{\circ}$ of correction per level. Therefore, the indication of multilevel SPO is smooth kyphosis including AS and Scheuermann's disease [5]. PSO is a closing wedge osteotomy (CWO) with shortening the middle and 
posterior column of vertebral body, the hinge is located in the anterior aspect and the correction angle for one level PSO was approximately $35^{\circ}$ [9]. PSO was the most popular technique for treatment of rigid kyphosis like AS, post-traumatic kyphosis (PTK) and spinal tuberculosis. For severe and rigid kyphosis, two-level PSO showed satisfactory correction, but the surgical time and blood loss were increased significantly [10]. The contact of upper and lower surface of closing wedge vertebra facilitates the bony fusion for PSO, but over shortening of the posterior column could compress the dura sac and increase the risk of neurologic complications [2]. Although VCR could achieve the strongest deformity correction, the related complications were much higher than other techniques [11]. Zhang et al. reported a modified osteotomy technique of VCD, which was a combination of several osteotomy techniques including SPO, PSO, COWO and eggshell techniques [4]. VCD showed better kyphosis correction angle than PSO with less decancellation of middle column (MC) and reduced the dura sac buckling than PSO. However, the hinge of VCD was located in the vertebral body and the exact hinge site was not easy to control.

In this study, we introduced a new technique of transpedicular open wedge osteotomy (TPOWO) for treatment of rigid thoracolumbar kyphosis in patients with AS. The osteotomy site of TPOWO was located in the pedicle level and parallel to the vertebral endplate, the procedure of vertebral body decancellation could be abbreviated and the hinge was located in the posterior aspect of the vertebral body. This kind of novel osteotomy strategy simplified the surgical procedure and achieved a satisfactory deformity correction. We described the detailed steps of TPOWO technique and evaluated the radiographic and clinical outcomes of this new technique.

\section{Materials And Methods}

\section{Subjects}

18 AS patients (14 male, 4 female) with thoracolumbar kyphosis who had underwent one-level TPOWO from January 2011 to December 2018 in our institute were reviewed retrospectively. The inclusion criteria were as follows: the global kyphosis angles were greater than $45^{\circ}$; patients who showed sagittal imbalance; more than 12 months follow-up. The exclusion criteria were patients who were diagnosed as spinal tumor, infections or history of previous spinal surgeries. This study was approved by the institutional review board (IRB) of our institute (K20190216).

\section{Radiographic Measurements and Clinical Outcome Evaluations}

Freestanding whole spine and pelvis anteroposterior and lateral radiographs were obtained before surgery, one week after surgery and at last follow-up for all patients. Three dimensional computed tomography (3-D CT) and magnetic resonance imaging (MRI) were performed before and one week after surgery. The radiographic parameters including sagittal vertical axis (SVA: the distance between C7 plumb line and the posterosuperior corner of S1), thoracic kyphosis (TK: the Cobb angle between the superior endplate of T5 and the inferior endplate of T12), lumbar lordosis (LL: the Cobb angle between the inferior endplate of T12 and the superior endplate of S1), thoracolumbar kyphosis (TLK: the Cobb angle between the superior endplate of T10 and the inferior endplate of L2), pelvic incidence (PI: the 
angle between a line from the center of the femoral head to the midpoint of sacral endplate and a line orthogonal to the sacral endplate), pelvic tile (PT: the angle formed by a vertical line from the center of the femoral heads and the line through the center of the femoral heads and the midpoint of sacral endplate), sacral slope (SS: the angle between the sacral endplate and horizontal), height of the anterior column of osteotomized vertebra (AC), height of posterior column of osteotomized vertebra (PC) were measured. Sagittal translation was defined as more than $2 \mathrm{~mm}$ displacement of the posterior edge between cephalad and caudal parts of osteotomized vertebra. The bony fusion was evaluated by the standards described by Brantigan and Steffee [12]. The operation time, blood loss and perioperative complications were collected. Scoliosis Research Society outcomes instrument-22 (SRS22) was assessed before surgery and at last follow-up to evaluate clinical improvement.

\section{Surgical Technique}

After general anesthesia, patient was placed prone over the reversed $V$ flexed operation table, the abdomen was free by padding the chest and iliac crest to avoid vena cava compression. A standard posterior midline skin incision was made, after exposed the laminae and transverse processes of adequate levels, multiaxial long-arm pedicle screws were inserted bilaterally three segments above and three segments below to the osteotomized vertebra, temporally pedicle screws were implanted in the osteotomized vertebra, screw diameter and length was estimated by the measurement of preoperative axial CT images to achieve maximum pull-out strength. Then, the spinous process, lamina and bilateral facet joints of osteotomized vertebra were removed (Figure 2B, C). After removing the ipsilateral temporally pedicle screw, intrapedicular osteotomy parallel to the endplate was performed through the screw trajectory using the osteotome designed by us (Figure 1). The osteotome contained a mobile nail in the centre shaft, a depth-restrictive device was outside the osteotome to restrict the osteotomy length. The required osteotomy length could be estimated from the preoperative CT measurement. Four-stepped vertebral body cleft procedure was performed for each side (Figure 3). First step, the osteotome was hammered through the previous pedicle screw trajectory until the anterior edge of the osteotome touched the anterior cortex of vertebral body, inner nail was inserted and made a hole on the anterior cortex (Figure $3 \mathrm{~A}$ ); Second step, the a diverged osteotomy to split the outer cortex of pedicle and vertebral body, another hole was made on the anterior cortex by the inner nail (Figure 3B); Third step, the osteotome was oriented with $30 \sim 40^{\circ}$ converge to cleft the inner cortex of pedicle and medial part of vertebral body, the third hole was made on the anterior cortex by the inner nail (Figure 3C); Fourth step, the dura sac and nerve root were retracted and protected by root retractor gently, the osteotome was hammered with $40 \sim 45^{\circ}$ converge to cleft the posterior wall of vertebral body with the fourth whole was made on the anterior cortex (Figure 3D). After that, the same procedure was repeated in the contralateral side. Neither pedicle substraction nor vertebral decancellation was carried out. The rods were bended based on the preoperative design, after leveling the operating table smoothly, the rods were connected with the 3 cephalad pedicle screws and the screw nuts were tightened. Subsequently, the rods were gradually pushed down to the caudal 3 pedicle screws until we heard a clear sound of cortical bone crack from the anterior cortex which implied the anterior cortex was open. After the rods were contacted to the caudal screws, the remaining nuts were tightened and the deformity correction procedure was completed. Other than the PSO or VCD, the hinge of 
TPOWO was located in the posterior edge of the vertebral body (Figure 2D, Figure 4C and Figure 4D). Motor and somatosensory-evoked potential monitoring was performed routinely for all patients.

\section{Statistical Analysis}

The data were analyzed by SPSS software package (version 23.0, IBM corp., Chicago, IL, USA). One-way ANOVA was used to evaluate the preoperative, postoperative and last follow-up radiographic parameters. For non-parametric data, Kruskal-Wallis test was used. Preoperative and last follow-up SRS-22 scores were evaluated by paired t test. $P<0.05$ was considered statistically significant.

\section{Results}

\section{Surgical Outcomes}

All patients received one-level osteotomy, the osteotomy level was T10 for 1 case, T12 for 3 cases, L1 for 7 cases, L2 for 5 cases and L3 for 2 cases. The mean operating time and estimated blood loss were 236 minutes (rage, $185-320$ minutes) and $595 \mathrm{ml}$ (range, 400-900 ml), respectively. The mean follow-up time was 33 months (range, 24-49 months). No intraoperative acute complication such as massive bleeding or great vessel injury was occurred. 3 patients experienced cerebrospinal fluid (CSF) leakage because of the adhesion between dura mater and ligament flavum during laminectomy, after bed rest and conservative treatment, all patients recovered within 2 weeks. 1 patient showed lower extremity numbness, the symptom was relieved after 2 months. There was no deep wound infection or paralysis occurred in any patients. Solid fusions were achieved in all the patients after 12 months according to radiographic evaluation. The gaps between osteotomized vertebrae were filled with newly formed bone (Fig 4F). No screw loosening, screw or rod breakage was noticed during the follow-up.

\section{Radiographic and Clinical Results}

The SVA, TK, PT and TLK angles were decreased significantly at one-week after surgery and maintained well until last follow-up when compared to pre-operation $(p<0.001)$; The parameters of $L L, S S$ and height of $\mathrm{AC}$ of osteotomized vertebrae were increased significantly at one-week after surgery and last follow-up when compared to pre-operation ( $p<0.001$ ); However, the height of MC of osteotomized vertebrae did not change significantly among pre-operation, one-week after surgery and last follow-up (Table 1). SRS-22 questionnaire scores were improved significantly at last follow-up then before surgery (Table 2).

\section{Discussion}

The highlight of TPOWO is that the osteotomy procedure is simplified by two major steps: transpedicular transection of vertebral body with osteotomy and correct the kyphosis by the hinge located in the posterior aspect of vertebral body. To improve the surgical efficiency, we utilized a special osteotome, which contained a nail in the center of it. When the anterior edge of osteotome reached the anterior cortex of vertebral body, we hammered the inner nail to create some holes on the anterior cortex to make it 
fragile. We just need 4 steps to complete the osteotomy procedure in each side by changing the directions of osteotome. Therefore, the curettage of intervertebral cancellous bone is unnecessary and the whole osteotomy procedure only needs 10-20 minutes. Radiographic results indicated that single level TPOWO showed more than $40^{\circ}$ of sagittal deformity correction in average. It was reported that the maximum deformity correction angle for one level PSO should be less than $40^{\circ}$ 冈if over correction was attempted, the acute shortening of the dura sac would affect the vascular circulation of spinal cord [2]. Furthermore, the over compression of dura sac could provoke neurologic complications [13]. Kawahara et al. performed an experiment using dogs to clarify the effect of acute thoracolumbar (T13) shortening on the spinal cord evoked potential and spinal cord blood flow [14]. The results showed that the dura sac became shrinking and buckling after one-third to two thirds of vertebral column shortening, more than two-third of vertebral column shortening increased potential of neurologic deficit and decreased the blood flow of spinal cord. Recent study of middle thoracic shortening test in canine model also showed that the safe range was within $1 / 3$ of a vertebral height shortening with two-segment laminectomy [15]. Accordingly, for those of severe kyphosis patients who requires more than $40^{\circ}$ correction angle, single level PSO could not achieve satisfactory kyphosis correction. Two-level PSO could provide enough correction angle, but the blood loss and operation time increased significantly [10]. To overcome these shortcomings, modified osteotomy techniques were investigated. Wang et al. presented a new technique of VCD with the hinge located in the vertebral body $[4,16-18]$. VCD could provide $10^{\circ}$ larger correction angle with $10 \mathrm{~mm}$ less shortening of the MC when compared to PSO. VCD is an alternative to PSO for correcting severe kyphosis, but the MC shortening still could not be avoided completely and the accurate decancellation of the vertebral body is not easy to control.

Compared to abovementioned osteotomy techniques, our technique could avoide posterior column shortening minimally. There was no neurologic deficit observed during or after surgeries in this study. Although this is a retrospective study without control group, the blood loss and operation time were significantly lower than previous studies of PSO or VCR $[8,17]$. The preservation of cancellous bone and close contact between posterior edge of osteotomized vertebra may decrease the blood loss from the cancellous bone. Also, we did not dissect the paravertebral mussels around the osteotomized vertebra. The integrity of muscles and soft tissues decreased the translation of the osteotomized surface during the osteotomy and subsequent mechanical correction [19]. The preservation of cancellous bone of MC could also increase the spinal stability and benefit to the bony union between osteotomized surfaces. In this study, none of the patients showed sagittal or lateral translation of osteotomized site during surgeries or follow-up period, the radiographic study after 12 months showed sufficient new bone formation was observed between the osteotomized gaps in all patients. At last follow-up, the correction maintained well and no instrumentation failure including rod or pedicle screw breakage was observed. These results indicate that TPOWO might be a safe and effective technique for correcting thoracolumbar kyphosis of ankylosing spondylitis.

As an open wedged osteotomy, the aorta injury should be highly considered in TPOWO. Aorta injury is a catastrophic complication in osteotomy surgery. It may be correlated to the elongation of the aorta during the deformity correction or the translation of the osteotomized surfaces which is not stabilized by internal 
fixation, especially when the elasticity of the arterial wall is reduced by atheromatous deposits or calcification [20]. Weatherley et al reported two cases of vascular injury associated with closing wedge osteotomy for AS in 1988 [21]. Both of them suffered aorta rupture which was confirmed in the postmortem findings. The other three cases of aorta rupture after spinal osteotomy were reported in 1956, 1971 and 1986, respectively [22-24]. Over-distraction of aorta during surgery was considered to be the possible mechanism of aorta rupture. However, recent studies showed that although the length of aorta increased more than $2 \mathrm{~cm}$ after osteotomy, there was no aorta rupture occurred when internal fixation was applied $[25,26]$. Liu et al reported that the length of aorta was increased approximately $2 \mathrm{~cm}$ for $39^{\circ}$ of kyphosis correction in closing wedge osteotomy [26]. Chang et al also reported that the mean aorta lengthening was increased to $2.8 \mathrm{~cm}$ (range, 1.7-3.5 cm) at the COWO [6]. In our study, the mean increase of the height of anterior column was $1.4 \mathrm{~cm}$ in average, there was no aorta rupture occurred during or after surgeries in our patients. We hypothesized that translational shear force during the deformity correction might be a higher risk factor than the vessel lengthening for aorta injury. In Weatherley's report for two patients with aorta injury, they did not add internal fixation for one patient and applied Harrington instrumentation for another patient. Without strong internal segmental instrumentation, the translational movement of the osteotomized surface is still exist. However, the exact mechanism of aorta injury during spinal kyphosis correction needs further experimental supporting. Although pedicle screws and temporary rod could provide sufficient stability to the osteotomized interface, but the correction procedure should be performed smoothly to avoid repeated irritation or sudden distraction of aorta. To improve the safety, we created some holes on the anterior cortex of vertebral body using our specially designed osteotome. These holes made the anterior cortex fragile and vulnerable to the bending and distraction forces, which avoided the sudden split of vertebral body and sharp bony spur formation. Although the great vessel related complication by spinal osteotomy was rare, the potential risk of aortic injury should be highly considered in patients who undergoing open wedge osteotomy. This study has some limitations, it was a retrospective study with small cases and no control group was set. Therefore, a controlled prospective study is needed to further prove the effectiveness, safety and long-term outcomes of this technique.

\section{Conclusion}

TOWO might be a safe and effective strategy for correcting rigid thoracolumbar kyphosis secondary to AS. The MC preservation minimizes the shortening of posterior column and prevents the over compression of dura sac, which also benefits to save operating time and decreases the blood loss. This modified and simplified osteotomy technique is easy to master and popularize.

\section{Abbreviations}

TOWO: transpedicular opening-wedge osteotomy; AS: ankylosing spondylitis; SVA: sagittal vertical axis; TK: thoracic kyphosis; LL: lumbar lordosis; TLK: thoracolumbar kyphosis; PT: pelvic tilt; SS『sacral slope; AC: anterior column; MC: middle column; SRS『scoliosis research society; SPO: Smith-Petersen osteotomy; 
PSO: pedicle substracion osteotomy; VCR: verterbral column resection; VCD: vertebral column decancellation; OWO: opening wedge osteotomy; CWO: closing wedge osteotomy

\section{Declarations}

\section{Acknowledgements}

Not applicable

\section{Authors' contributions}

Zhenghua Hong designed this study, devised the surgical technique and concepts, and performed the surgeries, and critically reviewed the manuscript. Guangbin Zheng collected patient data, prepared materials for IRB, did the statistical analysis, and and wrote the manuscript. Zhangfu Wang helped the study design, and critically reviewed the manuscript. Binbin Zheng did part of the clinical work, reviewed and analyzed all radiographic data. The authors read and approved the final manuscript.

\section{Funding}

Public Basic Research Programs Projects of Zhejiang Province, China (LGFl8H060012) grant fund was received to support this work.

\section{Availability of data and materials}

No additional data or materials are available.

\section{Declarations}

This study was approved by the institutional review board (IRB) of our institute (K20190216).

Since this was a retrospective review of usual care, informed consent was not required.

\section{Consent for publication}

Only anonymous patient data was used; therefore, consent for publication was not required.

\section{Competing interests}

The authors declare that they do not have any competing interests.

\section{References}

1. Ritchlin C, Adamopoulos IE. Axial spondyloarthritis: new advances in diagnosis and management. BMJ (Clinical research ed) 2021; 372:m4447. https://doi.org/10.1136/bmj.m4447. 
2. Chang KW, Chen YY, Lin CC, Hsu HL, Pai KC. Closing wedge osteotomy versus opening wedge osteotomy in ankylosing spondylitis with thoracolumbar kyphotic deformity. Spine 2005; 30(14):15841593. https://doi.org/10.1097/01.brs.0000170300.17082.49.

3. Qian BP, Wang XH, Qiu Y, Wang B, Zhu ZZ, Jiang J, Sun X. The influence of closing-opening wedge osteotomy on sagittal balance in thoracolumbar kyphosis secondary to ankylosing spondylitis: a comparison with closing wedge osteotomy. Spine 2012; 37(16):1415-

1423. https://doi.org/10.1097/BRS.0b013e318250dc95.

4. Zhang X, Zhang Z, Wang J, Lu M, Hu W, Wang Y, Wang Y. Vertebral column decancellation: a new spinal osteotomy technique for correcting rigid thoracolumbar kyphosis in patients with ankylosing spondylitis. The bone \& joint journal 2016; 98-b(5):672-678. https://doi.org/10.1302/0301$620 x .98 b 5.35726$.

5. Bridwell KH. Decision making regarding Smith-Petersen vs. pedicle subtraction osteotomy vs. vertebral column resection for spinal deformity. Spine 2006; 31 (19 Suppl):S171178. https://doi.org/10.1097/01.brs.0000231963.72810.38.

6. Chang KW, Cheng $\mathrm{CW}$, Chen $\mathrm{HC}$, Chang KI, Chen TC. Closing-opening wedge osteotomy for the treatment of sagittal imbalance. Spine 2008; 33(13):1470-

1477. https://doi.org/10.1097/BRS.0b013e3181753bcd.

7. Popa I, Oprea M, Andrei D, Mercedesz P, Mardare M, Poenaru DV. Utility of the pedicle subtraction osteotomy for the correction of sagittal spine imbalance. International orthopaedics 2016; 40(6):12191225. https://doi.org/10.1007/s00264-016-3126-2.

8. Garg B, Mehta N. Modified Posterior Vertebral Column Resection for Severe Spinal Deformity: A Retrospective, Comparative Study. The spine journal : official journal of the North American Spine Society 2020. https://doi.org/10.1016/j.spinee.2020.04.014.

9. Cho KJ, Bridwell KH, Lenke LG, Berra A, Baldus C. Comparison of Smith-Petersen versus pedicle subtraction osteotomy for the correction of fixed sagittal imbalance. Spine 2005; 30(18):2030-2037; discussion 2038. https://doi.org/10.1097/01.brs.0000179085.92998.ee.

10. Atici Y, Akman YE, Balioglu MB, Kargin D, Kaygusuz MA. Two level pedicle substraction osteotomies for the treatment of severe fixed sagittal plane deformity: computer software-assisted preoperative planning and assessing. European spine journal : official publication of the European Spine Society, the European Spinal Deformity Society, and the European Section of the Cervical Spine Research Society 2016; 25(8):2461-2470. https://doi.org/10.1007/s00586-015-3882-5.

11. Suk SI, Chung ER, Lee SM, Lee JH, Kim SS, Kim JH. Posterior vertebral column resection in fixed lumbosacral deformity. Spine 2005; 30(23):E703-

710. https://doi.org/10.1097/01.brs.0000188190.90034.be. 
12. Brantigan JW, Steffee AD. A carbon fiber implant to aid interbody lumbar fusion. Two-year clinical results in the first 26 patients. Spine 1993; 18(14):2106-2107. https://doi.org/10.1097/00007632$199310001-00030$.

13. Xi YM, Pan M, Wang ZJ, Zhang GQ, Shan R, Liu YJ, Chen BH, Hu YG. Correction of post-traumatic thoracolumbar kyphosis using pedicle subtraction osteotomy. European journal of orthopaedic surgery \& traumatology : orthopedie traumatologie 2013; 23 Suppl 1:S59-66. https://doi.org/10.1007/s00590-0131168-3.

14. Kawahara N, Tomita K, Kobayashi T, Abdel-Wanis ME, Murakami H, Akamaru T. Influence of acute shortening on the spinal cord: an experimental study. Spine 2005; 30(6):613620. https://doi.org/10.1097/01.brs.0000155407.87439.a2.

15. Ji L, Ma X, Ji W, Huang S, Feng M, Li J, Heng L, Huang Y, Lan B. Safe range of shortening the middle thoracic spine, an experimental study in canine. European spine journal : official publication of the European Spine Society, the European Spinal Deformity Society, and the European Section of the Cervical Spine Research Society 2020; 29(3):616-627. https://doi.org/10.1007/s00586-019-06268-8.

16. Xin Z, Zheng G, Huang P, Zhang X, Wang Y. Clinical results and surgery tactics of spinal osteotomy for ankylosing spondylitis kyphosis: experience of 428 patients. Journal of orthopaedic surgery and research 2019; 14(1):330. https://doi.org/10.1186/s13018-019-1371-y.

17. Wang T, Zheng G, Wang Y, Zhang X, Hu F, Wang Y. Comparison of 2 Surgeries in Correction of Severe Kyphotic Deformity Caused by Ankylosing Spondylitis: Vertebral Column Decancellation and Pedicle Subtraction Osteotomy. World neurosurgery 2019; 127:e972e978. https://doi.org/10.1016/j.wneu.2019.04.011.

18. Wang Y, Xue C, Song K, Wang T, Hu W, Hu F, Hao Y, Zhang Z, Wang C, Yang X et al. Comparison of loss of correction between PSO and VCD technique in treating thoracolumbar kyphosis secondary to ankylosing spondylitis, a minimum 2 years follow-up. Journal of orthopaedic surgery and research 2019; 14(1):137. https://doi.org/10.1186/s13018-019-1170-5.

19. Cheng J, Song K, Liang Y, Tang X, Wu B, Zhang G, Zhao Y, Wang Z. Spontaneous Remodeling of Spinal Canal After Sagittal Translation in Pedicle Subtraction Osteotomy for Correction of Thoracolumbar Kyphosis in Ankylosing Spondylitis. World neurosurgery 2019; 128:e245-

e251. https://doi.org/10.1016/j.wneu.2019.04.128.

20. Yelamarthy PKK, Mahajan R, Rustagi T, Tandon V, Sangondimath G, Chhabra HS. Aortic Rupture During Surgical Management of Tubercular Spondylodiscitis. Cureus 2018; 10(3):e2255. https://doi.org/10.7759/cureus.2255.

21. Weatherley C, Jaffray D, Terry A. Vascular complications associated with osteotomy in ankylosing spondylitis: a report of two cases. Spine 1988; 13(1):43-46. https://doi.org/10.1097/00007632- 
$198801000-00010$.

22. Lichtblau PO, Wilson PD. Possible mechanism of aortic rupture in orthopaedic correction of rheumatoid spondylitis. The Journal of bone and joint surgery American volume 1956; 38-a(1):123-127.

23. Klems H, Friedebold G. [Rupture of the abdominal aorta following a corrective spinal operation for ankylopoeitic spondylitis]. Zeitschrift fur Orthopadie und ihre Grenzgebiete 1971; 108(4):554-563.

24. Camargo FP, Cordeiro EN, Napoli MM. Corrective osteotomy of the spine in ankylosing spondylitis. Experience with 66 cases. Clinical orthopaedics and related research 1986(208):157-167.

25. Ji ML, Qian BP, Qiu Y, Wang B, Zhu ZZ, Yu Y, Jiang J. Change of aortic length after closing-opening wedge osteotomy for patients with ankylosing spondylitis with thoracolumbar kyphosis: a computed tomographic study. Spine 2013; 38(22):E1361-1367. https://doi.org/10.1097/BRS.0b013e3182a3d046.

26. Liu H, Qian BP, Qiu Y, Mao SH, Qu Z, Wang B, Yu Y, Zhu ZZ. Does the Traversing Length of the Aorta Change After Closing Wedge Osteotomy for Ankylosing Spondylitis Patients With Thoracolumbar Kyphosis?: A Magnetic Resonance Imaging Investigation. Spine 2017; 42(2):106112. https://doi.org/10.1097/brs.0000000000001781.

\section{Tables}

Table 1 Radiographic Assessment of Preoperative, Post-operative and Last follow-up Data

\begin{tabular}{|c|c|c|c|c|}
\hline Parameters & Pre-operative & Post-operative & Last follow-up & $P$ \\
\hline SVA $\triangle \mathrm{mm} \rrbracket$ & $158.97 \pm 55.80$ & $63.02 \pm 47.84^{\mathrm{a}}$ & $66.72 \pm 47.84^{\mathrm{b}}$ & $<0.001$ \\
\hline $\mathrm{LL}^{\circ} \rrbracket$ & $8.30 \pm 24.43$ & $36.61 \pm 13.73^{a}$ & $38.23 \pm 15.66^{b}$ & $<0.001$ \\
\hline $\mathrm{TK}^{\circ} \mathbb{\nabla}$ & $51.24 \pm 18.21$ & $33.02 \pm 11.45^{\mathrm{a}}$ & $35.96 \pm 11.35^{b}$ & $<0.001$ \\
\hline $\mathrm{PT} \mathbb{\otimes}^{\circ} \mathbb{Q}$ & $43.63 \pm 5.30$ & $25.91 \pm 8.48^{a}$ & $27.21 \pm 8.22^{b}$ & $<0.001$ \\
\hline $\mathrm{SS} \mathbb{D}^{\circ} \mathbb{D}$ & $19.67 \pm 9.40$ & $29.12 \pm 8.82^{a}$ & $28.13 \pm 6.79^{b}$ & $<0.001$ \\
\hline $\mathrm{TLK}^{\circ}{ }^{\circ}$ & $41.74 \pm 11.16$ & $7.37 \pm 7.46^{\mathrm{a}}$ & $8.67 \pm 7.35^{b}$ & $<0.001$ \\
\hline $\mathrm{AC} \triangle \mathrm{mm} \rrbracket$ & $25.17 \pm 3.94$ & $39.51 \pm 5.65^{\mathrm{a}}$ & $37.59 \pm 6.25^{b}$ & $<0.001$ \\
\hline $\mathrm{MC} \rrbracket \mathrm{mm} \rrbracket$ & $28.08 \pm 3.20$ & $27.22 \pm 4.01$ & $26.41 \pm 4.24^{b}$ & 0.507 \\
\hline
\end{tabular}

SVA sagittal vertical axis, LL lumbar lordosis, TK thoracic kyphosis, PT pelvic tilt, SS sacral slope, TLK thoracolumbar kyphosis, $\mathrm{AC}$ anterior column, $\mathrm{MC}$ middle column

aSignificant difference between post-operative and preoperative: $p<0.001$ 
${ }^{b}$ Significant difference between last follow-up and preoperative: $p<0.001$

Table 2 Comparison of Preoperative and Last Follow-up Data of Scoliosis Research Society-22 (SRS22) outcomes

\begin{tabular}{llllll}
\hline Parameters & Pain & Function & Appearance & Mental & Satisfaction \\
\hline Pre-operative & $1.71 \pm 0.40$ & $2.27 \pm 0.43$ & $1.94 \pm 0.58$ & $1.79 \pm 0.37$ & $1.53 \pm 0.30$ \\
\hline Last follow-up & $4.27 \pm 0.31$ & $4.34 \pm 0.35$ & $4.32 \pm 0.42$ & $4.39 \pm 0.33$ & $4.64 \pm 0.33$ \\
\hline$p$ & $<0.001$ & $<0.001$ & $<0.001$ & $<0.001$ & $<0.001$
\end{tabular}

\section{Figures}




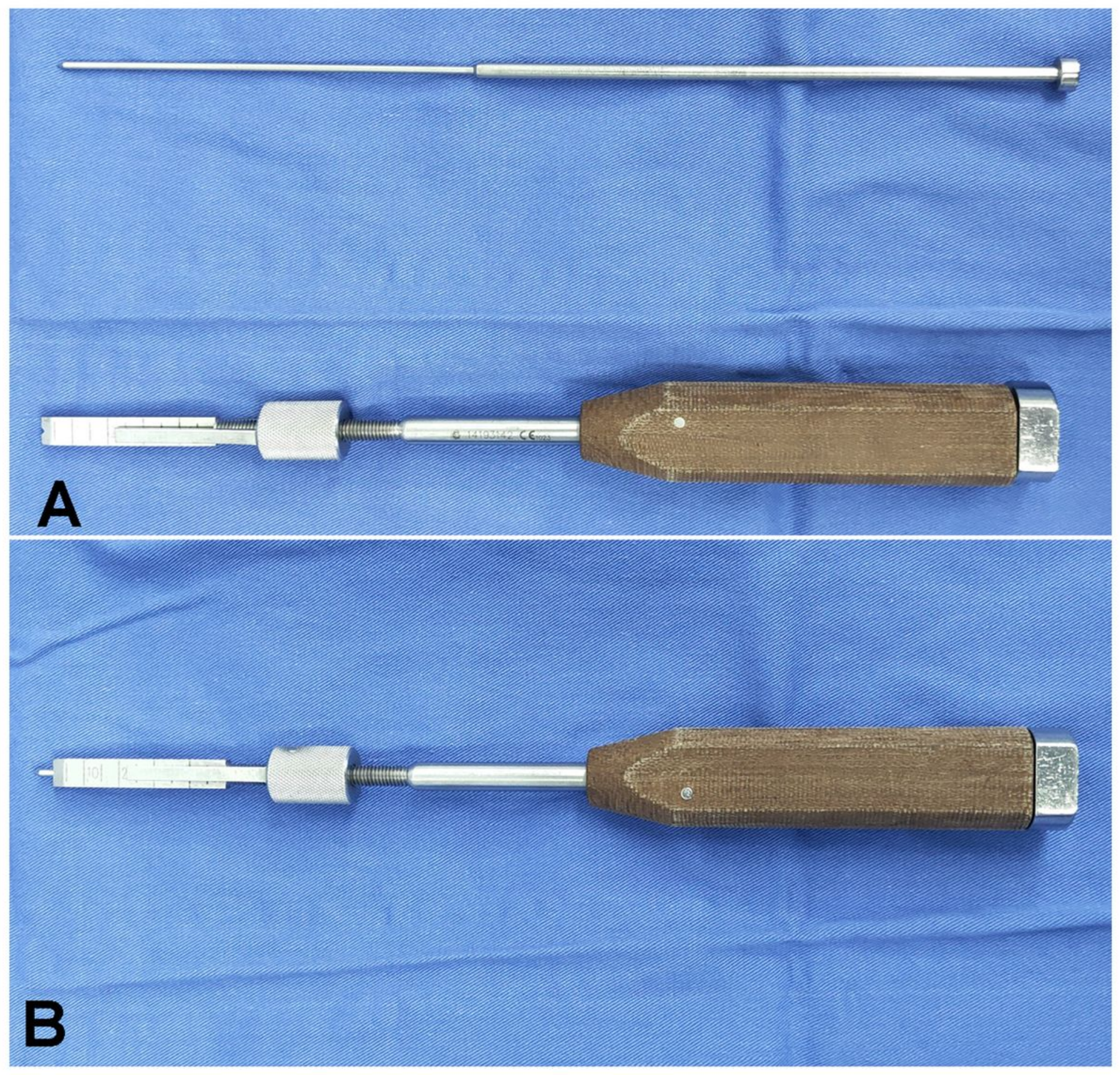

\section{Figure 1}

a, The osteotome is made up of main part with a depth-restrictive device and an inner nail, the width is $8 \mathrm{~mm}$ and the thickness is $4 \mathrm{~mm}$. b, After inserting the nail into the osteotome, the top of the nail could be protruded from the osteotome. 

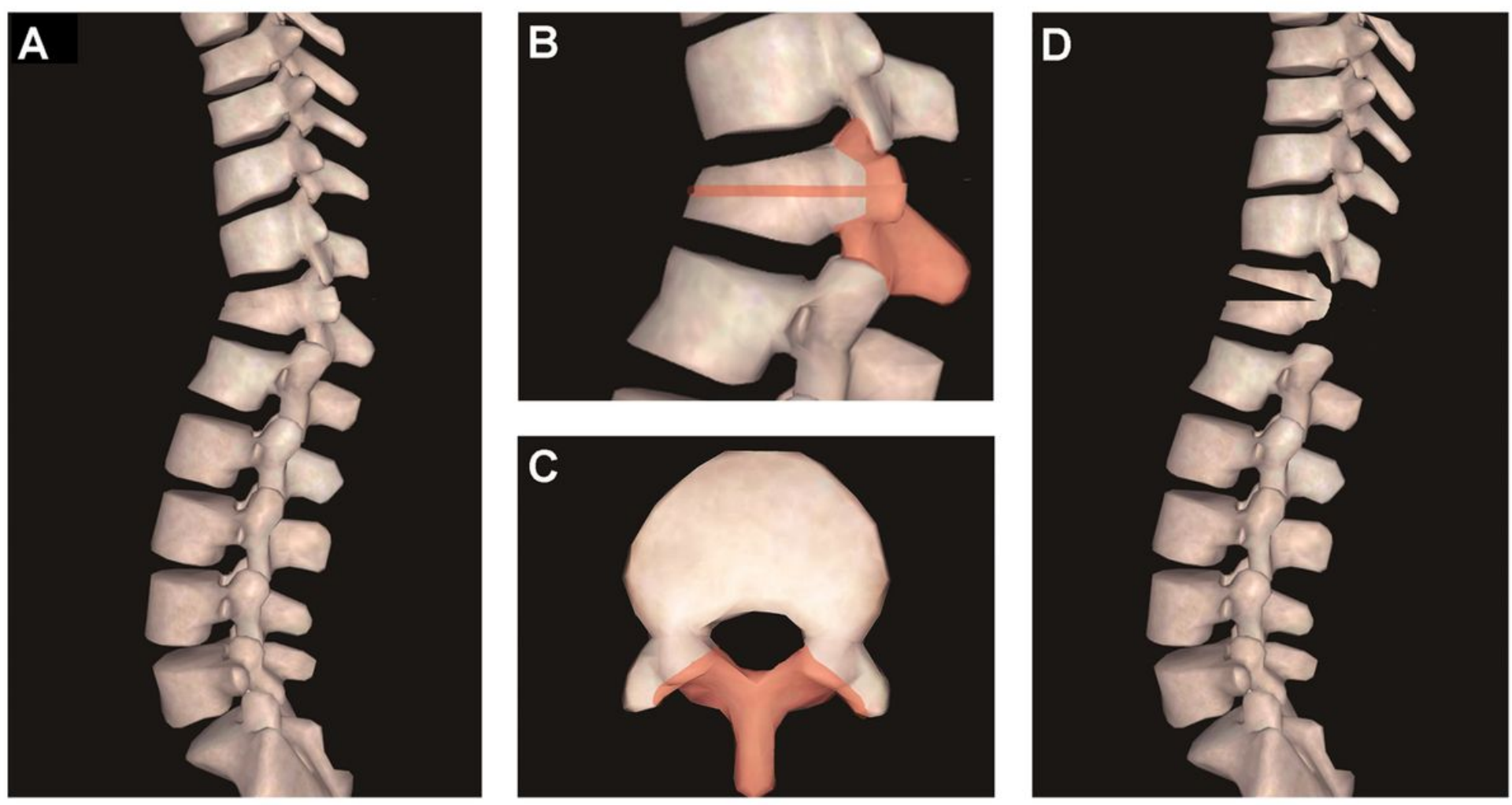

Figure 2

Diagrams of middle-column preserved transpedicular opening-wedge osteotomy (TOWO). b and c, The spinous process, lamina and facet joints were removed, the direction of osteotomy was parallel to the endplate (The red portion). $d$, The correcting hinge was located on the posterior edge of the vertebral body, which could create an open wedge of anterior column.
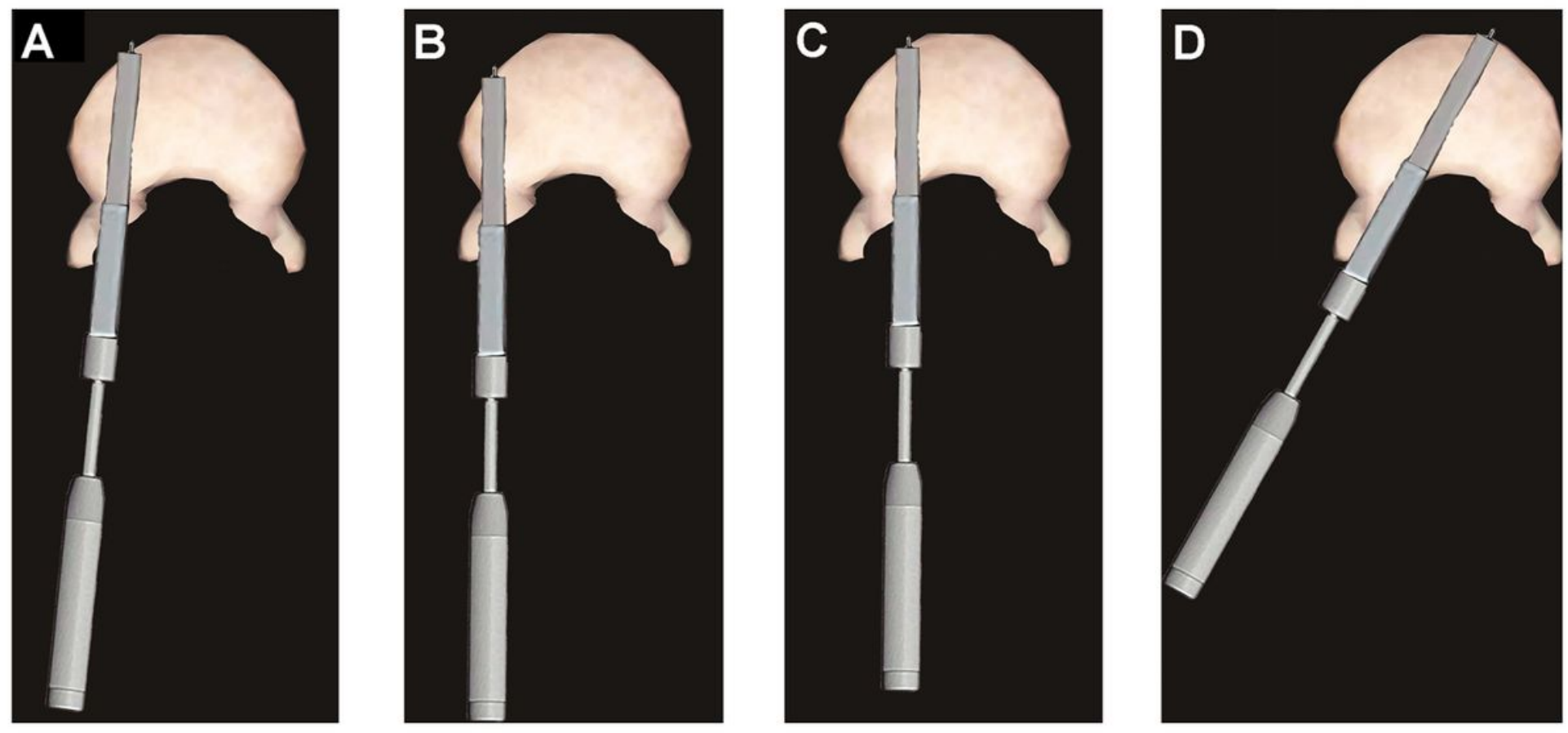

Figure 3 
Diagrams of four-stepped osteotomy. The osteotomy was performed in four different directions to cleft the outer and inner cortex of vertebral body in each side, eight holes were made on the anterior cortex by the projecting nail tip to fragile the cortex.
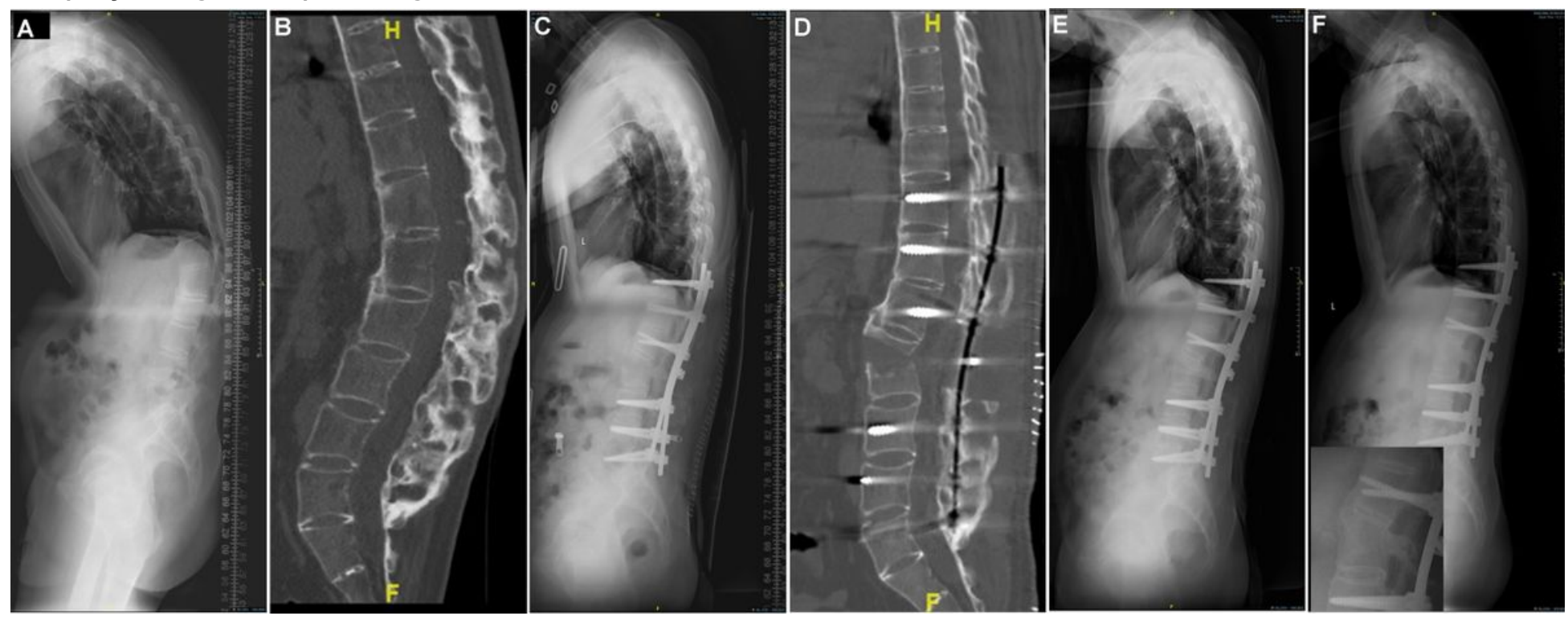

\section{Figure 4}

A 36-year-old male patient with thoracolumbar kyphosis secondary to ankylosing spondylitis. $a$ and $b$, Thoracic kyphosis (TK), lumbar lordosis (LL), thoracolumbar kyphosis (TLK), the sagittal vertical axis (SVA), the height of middle column (MC) and anterior column (AC) were $43^{\circ}, 14.9^{\circ}, 30.3^{\circ}, 132 \mathrm{~mm}$, $31.2 \mathrm{~mm}$ and $27.6 \mathrm{~mm}$, respectively before surgery. $c$ and $d$, One week after surgery, the TK, TLK and SVA were decreased to $41^{\circ}, 2.9^{\circ}$ and $30 \mathrm{~mm}$, respectively, the $L L$ and height of $A C$ were increased to $39.2^{\circ}$ and $43.4 \mathrm{~mm}$, respectively, the height of $\mathrm{MC}$ was $30.8 \mathrm{~mm}$, which was similar to preoperatively. e and f, At 4 months and 2-year follow-up, the correction was maintained well, the height of AC were $43.1 \mathrm{~mm}$ and $42.6 \mathrm{~mm}$, respectively; at 2-year follow-up, new bone formation could be observed between the gap of open wedged vertebra, which implied bony fusion was achieved. 